\title{
Use of stereotypical social gender roles in an L2 narrative construal task by advanced, Polish learners of English
}

\author{
Janusz Badio
}

University of Łódź, Poland

\begin{abstract}
The article presents a study of the process of comprehension of an input joke and its subsequent retelling in writing by Polish advanced students $(n=36)$ of English as a foreign language. The research question was whether people are guided by stereotypical social gender roles and cultural schemata during comprehension and production of a joke involving events that make up a story. The joke included references to female (wife) and male (husband) participants as well as a secretary (gender not specified), names Gloria and Mike and a number of objects such as: violets, chocolates, handbag or laptop. It was predicted that the VM version of the joke (the version with the name Mike, supposedly male secretary) would take the participants more time to interpret as compared to the VF version (with Gloria as a most possible candidate for the secretary role). This hypothesis was indeed confirmed, but the experimental subjects did not take significantly more time to write their versions (VM and VF conditions) of the story. The qualitative analysis demonstrated variable cultural bias during the construction of the participants' roles and relations, often against or in the absence of clear instructions in the input to do so.
\end{abstract}

Keywords: comprehension, production, cultural schemata, bias, construal, narrative, story, events

\section{Introduction}

Narratives and stories are complex units of thought and language. Shorter or longer, more or less formal, they are produced and shared in variable contexts for different reasons and effects. Narratives do not exist in some cognitive vacuum but belong to specific cultures and communities, styles of life, religions, communities and economies.

Badio (2019, submitted) has recently argued that they form a radial category (Evans \& Green, 2006) whose prototype may be a most schematic conception of the so-called action chain model (Langacker, 1991, p. 283). The model describes forceful interactions in the physical world with objects analogised to events 
and forces to causes. Other, more local prototypes may be types of stories occasioned in a round of stories, jokes, advertisements, poems, imagined scenarios during children's play, narratives presenting problems, narratives as performances, environmentally cued narratives or tactical narratives (Ervin-Tripp \& Küntay, 1997, pp. 149-160). In short, narrative has been demonstrated to form a network of related, albeit complex cognitive, communicative, linguistic and cultural units that require effortful mental construal and language coding of perspective, level of schematicity, temporality and causality, to mention only a few parameters.

Influential research into narrative structure, coherence, causality and temporality as well as the use of so-called ordinary events, i.e. events seemingly too obvious and mundane for presentation (Labov \& Waletzky, 1967; Labov, 1997, $2001,2004,2006,2011)$ has instructed us to look not only at language meaning but how such construed meaning is coded with language form (Squire, 2005).

The construal of a story involves selection of agents, participants, objects, intentions, temporal scope, orienting commentary, causality links and cultural schemata. This article has a goal of describing an experimental study in which advanced second language Polish learners of English were instructed to write stories on the basis of a joke. The joke presented a list of expenses from a petty cash book of a small business (Misztal, 1990). The sections that follow this brief introduction deal with the research questions, hypotheses, materials, procedures, creation of a mini-corpus (10,000 words) and the presentation of results. These involve both qualitative analysis of how the participants construed their versions of the input story and quantitative outlook on the data involving descriptive and inferential statistics obtained to confront the questions regarding the main variables.

\section{General and research questions}

Thus, the general question asked in the present study concerns the use of stereotypical and culturally specific (all participants were Polish) gender roles during the process of constructing a story following the presentation of the joke. Such culturally specific stereotypes presumably guide understanding of typical social roles, uses of objects in events or expected temporal scope of event sequences, cause-effect links, consequences of human action and expected behaviour. As an example, Giora (2003) demonstrated how story comprehension can be strongly affected by such top-down processing.

A variety of schematic knowledge structures have been proposed that guide language use, both comprehension and production. Miller et al. (1960, pp. 16-64) discussed the importance of plans that: possess hierarchical organization, are co- 
gnitive/mental structures, are used to control the order of action and operations, include a goal, are more or less detailed, can be focused on, imagined and learnt. Importantly, new plans arise from plans made in the past. They become conventionalised in the form of schematic scripts (Schank \& Abelson, 1977) that apart from specifications of participants' social roles also contain information on the sequence of actions to be taken. Another schematic type of knowledge structure, frame (cf. Charniak, 1975b; Minsky, 1975; Winograd, 1975 or Metzing, 1979) includes objects, people and places albeit without temporal organisation (e.g. the famous restaurant frame). In the case of such global patterns of knowledge as schemas, e.g. the narrative schema, events and states in sequences are arranged by proximity and causality (cf. Bartlett, 1932).

The general question about the use of stereotypical social gender roles in this study was operationalised in terms of the actual task to construct a story on the basis of a joke quoted below from Misztal (1990, p. 74). For lack of space, this author refrains from the presentation of different types of jokes. The important point to make, however, is that many jokes are short and they present selected, crucial events that help make up a story. Readers of these jokes activate necessary background information so the words and phrases only make sense against culturally relevant stereotypes and schemas.

\section{Extract from a petty cash book:}

April

1. Advertisement for a secretary

$£ 5$

3. Violets

$£ 1$

4. Candy

$£ 1.25$

8. Secretary's salary

$£ 30$

10. Flowers

$£ 2$

11. Candy for wife

$£ 1$

15. Secretary's salary

$£ 60$

18. Handbag

$£ 18$

19. Candy for wife

$£ 1.25$

22. Gloria's salary

$£ 90$

24. Theatre and dinner, Gloria and self

$£ 55$

25. Chocolates for husband

$£ 2$

28. Fur coat for wife

29. Advertisement for a male secretary

$£ 2,500.00$

$£ 5$

The reading of the above list of expenses constituting the joke triggers interpretative processes that relate the items of the list in time, space and causality. Readers construct the list of nominals on the list as important cues to construe a coherent set of events that form a story with the earlier event of employing a new 
secretary to the most reportable event of, presumably, the wife finding out about the affair and the need to buy her a fur coat. This author's schematic reading of the joke with some predictions regarding the roles of candy, violets, theatre outing, salary rise, change of the referring term from secretary to Gloria remained to be tested empirically. The numbers on the left show prices in pounds. An argument might be raised that they invoke some aspects of the British culture in the Polish participants of the study. However, despite some obvious cultural differences between Poland and UK, both countries are set in the European tradition in which family, marriage and courtship are understood similarly. Moreover, the study was interested in the way the Polish participants would deal with the input joke and the prices used in the input joke were not a variable across the different study groups.

\section{Hypotheses, operationalisations, mini corpus and the design of the experiment}

The experimental task involved reading (in two independent groups) two slightly different versions of the same baseline joke presented above. Whereas the VF version was the one in which the name used was Gloria, the VM version contained the name Mike instead of Gloria, new laptop for husband, no information at the end of the list regarding the gender of the secretary, theatre and dinner with Mike and self instead of Gloria and self. The following list summarizes these changes.

Independent variable: agreement or not with cultural schemata and stereotype

\section{Agreement (reference version)}

VF (version with the name Gloria, presumably the secretary's name)

8. Candy for wife

22. Gloria's salary

24. Theatre and dinner, Gloria and self

28. New fur coat for wife

\section{Disagreement (changed version)}

VM (version with the name Mike, presumably the secretary's name)

8. Candy for husband

22. Mike's salary

24. Theatre and dinner, Mike and self

28. New laptop for husband

Importantly, neither of the two versions of the joke made it clear whether the secretary was male or female. It was predicted that the analysis of the stories written in this task (regardless of which version the participants read) would reveal the tendency to stick to the cultural, stereotypical schemata in construing the role of the story participants (business owner, husband/wife, secretary) though there were no signals in the input to construct these roles in this way. 
The second independent variable accounted for in the qualitative analysis only was gender of the participants of the study. Some differences between stories written by female vs. male writers were predicted to appear due to variable gender roles imposed by Polish culture. This observation is also in line with research that demonstrated that people generally tend to assume their own (here either male or female) perspective on the observed events (Tversky \& Hard, 2009).

Having read the two different versions of the same joke, the participants wrote their stories. These were recorded in the format of the dBase of Microsoft Access with two tables (SPEAKERS and STORIES). The table containing STORIES $(n=36)$ had columns to be filled in with the following information: experimental condition (VM/VF), i.e. female/male, reading time of the input, writing time and length of a story in number of words.

The time the participants took to read and understand the input joke before they were ready to begin writing and the writing time itself were used as an operational definition of processing complexity. The participants who were instructed to read the VF (normal, baseline, reference) version of the joke were hypothesized to have an easier task than the ones whose version was VM (with changed, untypical or less expected) social roles for men and women. The relative ease or difficulty was connected with the joke being either compatible with the cultural schemata (VF condition) or not (VM condition). In sum, the following variables and operationalisations were applied.

a) Version of the joke, VM vs. VF, as an independent variable hypothesised to influence construal of the written story. It was predicted that the participants in the VM condition would tend to ignore the clues provided in the joke and would supply solutions agreeing with the cultural schemata and stereotypes as regards gender roles (directional hypothesis).

b) Gender (independent variable); it was hypothesised that there would be some differences in how the stories would be construed depending on whether the writer was male or female (non-directional hypothesis).

c) Reading and writing times (dependent variable) were hypothesized to be longer in the VM (changed cultural roles) condition.

\section{Task instructions and procedures}

The participants of this study ( $n=36$; Male $=18$; Female=18, all Polish) were advanced students of the Institute of English Studies at the University of Łódź, Poland and The Angelus Silesius Higher School of Applied Sciences in Wałbrzych, Poland. They agreed to participate in the project for additional credit. 
The students wrote the stories after classes in designated rooms. They were sat down and read the following instructions in Polish (here translated into English).

Participation in this study is completely anonymous and safe. The only details you will be asked to provide are whether you are male or female. You will see an extract from a petty cash book (page 2 of this document). Your task is to write a short story in response to the provided clues. The story must use sentences to form a complete text, not single words or phrases.

\section{Stage 1:}

When you hear the signal START, read the input joke and press the stopper watch provided. When you finish reading, press the stop button on the stopper that measures your reading time and enter your result onto the provided worksheet. Subsequently, write a story on the basis of the input joke. The teacher will be monitoring your work.

Stage 2:

As you are beginning to write, press the start button on the stopper and start writing. During the actual writing you can look up the list of cues provided. The teacher will be monitoring your work.

The effected stories (Group 1, VM, $n=18$ and Group 2, VF, $n=18)^{1}$ were digitized and recorded. The qualitative analysis of the data followed by the quantitative description and analysis of statistics is presented in sections five and six.

\section{Qualitative analysis of data}

\subsection{Stories written in the VF (version with the name Gloria, presumably the secretary's name)}

Stories $(n=18)$ written by students in this condition of the experiment were created following the presentation of the joke with unchanged (relative to the original joke) roles of the main participants: business owner, wife, Gloria, secretary. The task involved the interpretation of the roles of these participants and the objects

1 There were two independent groups of participants selected randomly. Group called VM read the version of the input joke that implied that the secretary was male, whereas the group called VF read the version of the input joke that implied the secretary was female. Both groups consisted of 18 participants, 9 female and 9 male. 
listed (e.g.: violets, flowers, candy, handbag, theatre, fur coat). The writers needed to construe and code in language the relations between the participants, the temporal scope of the key events, the most reportable event and how this event related to other events and objects causally.

First, many participants decided to begin their story version with an orienting section including different background parameters of the imagined context. Some expressions in this section, if present, designate time.

1) one day, it was a late afternoon in April, a few days ago, April was the month needing some changes

Some other refer to space and location.

2) in the park, there I was sitting in my office

Example sentences [3abc] below reflect the Polish cultural, stereotypical bias ${ }^{2}$ that secretaries are usually pretty women, which may then be taken as a reason and/or an excuse for men to flirt with them at work.

3) a) hired a secretary and she was very pretty

b) I found a new secretary. In order to make an impression on her I bought her violets and candy. Every woman likes flowers and sweets and I am a gentleman so I did it.

c) April wasn't a good month for John. His beautiful secretary quit her job ...

A few participants decided to include more evocative commentary in the orienting section of their stories.

4) a) Wind tugged playfully at leaves ...

b) ... grasses and violets in the park which Pheneas used to cross every day on his way to buy candy for his wife.

The narrator is usually $3^{\text {rd }}$ person, but there are some examples of writing from the point of view of the business owner, his wife or Gloria, the secretary.

Seven out of nine female writers in this condition decided that the secretary was female and that the boss made some advances to her. She received flowers from him as she was pretty or the boss gave violets to Gloria to impress her.

On the other hand, many potentially obvious clues that the joke was about office love affair were not so unambiguously interpreted. For example, one female writer

2 The stereotype is well documented on the Internet. Even a random search for a phrase such as boss flirts with secretary renders numerous links to the discussion of the stereotype as well as images. 
decided it was Gloria who gave candy for the businessman's wife as it was her duty. The boss and Gloria spent time at the theatre in another account of the joke and Gloria felt sorry, which was taken as the reason why she decided to present chocolates for her husband. One female writer construed the role of candy in a funny way, namely that the owner of the business organized a competition for secretaries to buy as many sweets for the wife for as little as possible. Another writer said that the boss indeed flirted with the secretary, but he then felt guilty and bought her an expensive fur coat, or that the wife read the petty cash book list of expenses and decided the couple could afford an expensive fur coat without any mention of a possible love affair between the boss and Gloria. Also, interestingly, one female writer said Gloria was not the secretary (which many other writers did) but the wife, and that is why the husband went to the theatre with her, also possibly this choice was dictated by the information in the input story that Gloria's salary was 90 pounds. The wife bought chocolates for the husband in return for spending a nice evening at the theatre. The reason why she received her pay rise was by some attributed to her diligence at work and professional approach, not the love affair between her and the boss.

Similarly to the female writers, stories written by men $(n=9)$ construed the role of the secretary as female. Candy, violets and flowers tended in these stories to be for Gloria, and often for the reason she was pretty. Gloria (secretary) bought flowers for her husband when she felt guilty for flirting with the boss. Her husband was also made jealous of Gloria when she was offered the job in the family business, which also agrees with the salient though outdated stereotypical cultural schema in Poland at least, according to which it is men who should be the busy bread winners and women should stay at home.

In sum, there is some data to suggest that both female and male writers in this condition tended to be guided by the cultural schema and stereotype of good family relations, a husband looking after his wife and hard work rather than the schema of office love affair and marital infidelity. However, there is also some indication that unlike female writers, men writers tended to focus more on the schema and stereotype of office love affair and marital infidelity. Not all writers accounted for every clue on the list provided in the joke.

\subsection{Stories written in the VM (version with the name Mike, presumably the secretary's name)}

Unlike the stories written in the control condition (see section 5.1 above), the ones written in this condition were created following the input joke which mentioned a secretary, Mike, some husband and wife as well as the same objects, i.e., violets, flowers, candy, handbag, but laptop for husband instead of fur coat for wife. These 
changes were used to signal to the reader that the wife should be construed as the owner of the business, whereas Mike as her secretary against the cultural expectations discussed above. Additionally, the clue that the husband received some chocolates was used to further counteract the top-down activation of the cultural schema according to which it is men who would be expected to buy chocolates for women rather than the other way round. The same comment applies to the final clue of the input joke, namely that the husband received a laptop and an advertisement was put up in the newspaper for a new secretary (male or female - not clear from the input joke).

Some stories of what happened in this condition included a new character, for example: Jane, Amanda or Sara, who became the bosses of the business. In one of the stories the name Mike was construed as the female boss's nickname. The female boss, however, did not tend to have a male secretary. Instead and against the provided clues, the cultural schema tended to suggest to some writers that they should construe Mike as a friend from work, friend from office, instructor or assistant and a new character (Cathy, Annie) needed to be invented to become the secretary in the story.

Even when Mike became a secretary, he was construed as giving advice to the woman-boss, as he seemed to be someone who is more knowledgeable than her. Moreover, when the female boss felt she was flirting with Mike the secretary, she felt guilty and bought her husband some chocolates and tickets to the theatre, where they spent some nice time together. So this outing was not construed as part of the love affair and marital infidelity. Alternatively, the visit to the theatre and the outing was the wife and her husband's and Mike was not involved. In one story from a female participant in this condition, Mike (construed as a young man in all stories) became the secretary, and he was so happy that he decided to buy flowers for the woman-boss. In another story, Mike became a secretary but when the business was good, the objects (handbag, candy, flowers) were what the woman boss bought for herself without hints of some love affair between her and Mike. In still another story Mike became a secretary, but bought flowers and Candy for his mother-in-law. There was also some tendency to construe emotions as typically female and they were presented as causes of the female boss's incapability of deducting some money from Mike's salary after he broke a laptop in one story. Another story admitted the female boss needed time for her husband and the kids.

Indeed, the writers in this condition had a more difficult task to interpret the role of the different clues in their input joke. Many of them ignored the easy option to make Mike the secretary, and if they did, Mike had some of the features stereotypically associated with men as dominating, more skilful and knowledgeable, or he became an assistant in order to avoid the word secretary, especially because in the Polish language this word is marked for feminine gender and its masculine counterpart has different connotations. The sekretarz 'male secretary' would be 
most probably associated with some high-ranking public function within a political party or a local government.

In conclusion, both stories written in the VF (control) and VM (changed) conditions of the experiment tended to be instructed by a cultural schema activated by different writers to attract the readers' attention to selected stereotypes of gender roles in the Polish communities the participants of this study came from. These beliefs and expectations often became more salient and stronger than the clues provided in the input joke. As a result, they guided the process of construing participant roles, objects, and causal relations. The next section six approaches the question whether the differences in the input jokes between the control and experimental groups led to different reading and writing times of the stories.

\section{Quantitative analysis}

The reading and writing times mentioned in passing earlier were used to operationalise the prediction that a cultural schema would be activated to guide the comprehension of the input joke (the petty cash book). The participants were divided into two independent groups, the VF $(n=18)$ (Gloria, control group) and the VM $(n=18)$ (Mike, experimental group) with equal number of female and male student participants in each group.

The writing times (controlled for by the experimenter) ${ }^{3}$ in both groups tended to be shorter when the reading time was shorter though there are also some exceptions. However, it is the differences between VM and VF groups that are more interesting (see Fig. 1 below).

The VF-control group (dark shade) tended to spend less time to read and interpret the input joke in comparison to the VM-experimental group. The reading times in the VF group also look more evenly distributed about the mean as opposed to the reading times in the VM group. These are in fact spread across the whole diagram. The comparison of how the writing times are distributed in the two groups is presented below in figure two.

The writers in the VM-experimental condition seem to have taken more time to construe their stories. Their graph is markedly shifted towards the longer intervals of the reading time. Besides, the results in the VM writing condition also seem to exhibit a larger spectrum of writing times.

3 The individual participants were asked to raise their hands when they completed the reading (and later writing) of their version of the input joke. Computer stopper was used to record individual reading/writing times. 


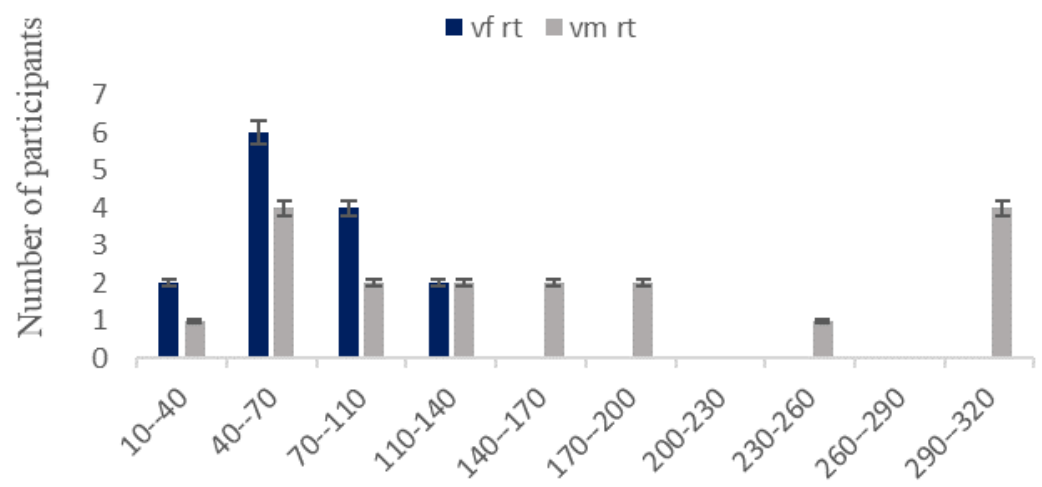

Intervals of reading time in seconds

Fig. 1. Distribution of data in the reading task between VF and VM groups with numbers of participants on the vertical and reading time on the horizontal axes

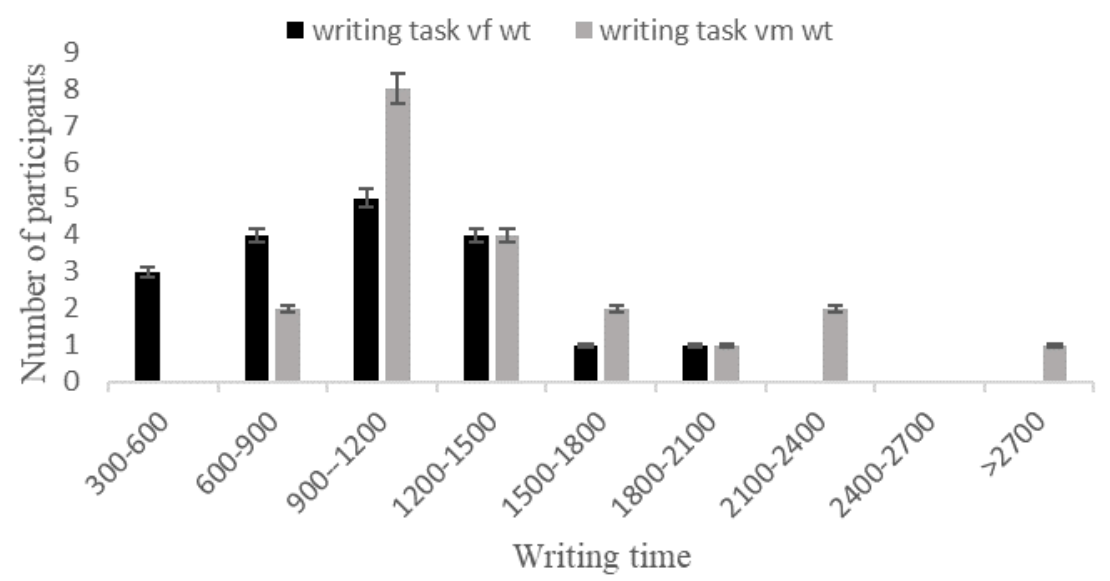

Fig 2. Distribution of data in the writing task between VF and VM groups with numbers of participants on the vertical and time on the horizontal axes

The difference in the reading times of the experimental group VMrt and the control VFrt group turned out to be significant ( $M f r t=156.7 \mathrm{sec}$.; $M m r t=101.5 \mathrm{sec}$.; $d f=31 ; S E$-combined $=28.8 \mathrm{sec}$.), and the value of the one-sided $t$-test assuming 
unequal variances $(t=1.91 ; p=.03)$ inclines one to accept the hypothesis that it was the manipulation of content of the input joke, i.e., the independent variable that caused this change in the reading time between the two groups.

However, the writing times between the two groups did not differ in a statistically significant way $(M m w t=1682.88 ; M f w t=1142.2 ; t=-1.5$; SE-combined $=359$ sec.; $p=.073$ ). This is a little surprising given the way the writing times of the two groups look on the graph (see Fig. 2 above). On reflection, the writing task may also have depended on other variables such as: speed of writing, day-dreaming despite the fact that each participant had the same amount to write. However, the time to interpret the input version of a joke was different in different participants, which is still another argument the writing time in the presented study turned out not to be very informative.

\section{Conclusions}

In conclusion, the difference in reading times between the experimental conditions turned out to be statistically significant. However, though the participants in the VM group took longer mean time to construct their stories compared with the VF group, the difference was not statistically significant at $\alpha=05$ and also potentially uninformative.

On reflection, the task to write followed the task to read and in order to interpret the roles and relations of the listed participants and objects. Once the plans of what to write had been in place, it may not have made much of a difference in terms of difficulty whether one wrote in the VM or VF condition. Also, one caveat against accepting the hypotheses of the quantitative study is its limited scope and a limited number of stories collected for analysis. Still, one can argue that at least in the reading task the effect of the top-down activation of a cultural schema and use of stereotypical social gender roles was robust. It caused that the readers in the VM condition took significantly more time to read and interpret the input joke. The qualitative analysis of the mini corpus of stories in section five clearly demonstrated that the writers were biased by the top-down activation of Polish cultural schemata and stereotypes of gender during the construction of the participants' roles and relations, often against or in the absence of clear instructions in the input to do so. 
Use of stereotypical social gender roles in an L2 narrative construal task...

\section{References}

Badio, J. (2020). Narrative as a radial category. Studia Anglica Posnaniensia (to appear in 2020).

Bartlett, F. C. (1932). Remembering: A Study in Experimental and Social Psychology. Cambridge: Cambridge University Press.

Charniak, E. (1975). Organisation and Inference in Frame-Like Systems of Common-Sense Knowledge. Catalogna: ISCS.

Ervin-Tripp, S. \& Küntay, A. (1997). Conversational stories. In T. Givon (Ed.), Conversation: Cognitive, Communicative and Social Perspective, (pp. 136-166). Amsterdam: John Benjamins.

Evans, V. \& Green, M. (2006). Cognitive Linguistics: An Introduction. Edinburgh: Edinburgh University Press.

Giora, R. (2003). On our Mind: Salience, Context and Figurative Language. Oxford: Oxford University Press.

Labov, W. (1997). Some further steps in narrative analysis. Journal of Narrative and Life History, 7, 395-415.

Labov, W. (2001). Uncovering the event structure of narrative. Georgetown University Round Table. (Georgetown: Georgetown University Press). Available online at: http://www.ling.upenn.edu/ wlabov/uesn.pdf (accessed 9 April 2004).

Labov, W. (2004). Ordinary Events. In C. Fought (Ed.), Sociolinguistic Variation: Critical Reflections, (pp. 31-43). Oxford: Oxford University Press.

Labov, W. (2006). Narrative pre-construction. Narrative Inquiry, 16, 37-45.

Labov, W. (2011). Oral narratives of personal experience. In P. C. Hogan (Ed.), The Cambridge Encyclopedia of the Language Sciences. Cambridge: Cambridge University Press. http://www.ling.upenn.edu/ wlabov/Papers/FebOralNarPE.pdf

Labov, W. \& Waletzky, J. (1967). Narrative analysis. In J. Helm (Ed.), Essays on the Verbal and Visual Arts, (pp. 12-44). Seatle: University of Washington Press.

Langacker, R. (1991). Foundations of Cognitive Grammar, Volume 1 and 2. Stanford: Stanford University Press.

Metzing, D. (1979). Frame Conception and Text Understanding. Berlin: de Gruyter.

Miller, G. A., Galanter, E., \& Pribram, K. H. (1960). Plans and the Structure of Behaviour. Harvard: Holt, Rinhart and Winston, Inc.

Minsky, M. (1975). A Framework for Representing Knowledge. In P. Winston (Ed.), The Psychology of Computer Visioni, (pp. 211-277). New York: McGraw Hill.

Misztal, M. (1990). Life in Jokes. Warszawa: Wydawnictwa Szkolne i Pedagogiczne.

Schank, R. \& Abelson, R. (1977). Scripts, Plans, Goals and Understanding. Hillsdale, NJ: Erlbaum.

Squire, C. (2005). Reading narratives. Group Analysis, 38(1), 91-107.

Tversky, B. \& Hard, B. M. (2009). Embodied and disembodied cognition: spatial perspetive taking. Cognition, 110, 124-129.

Winograd, T. (1976). Towards A Procedural Analysis of Semantics. Palo Alto: Stanford AI-TR 292. 